\title{
Pathogenesis of psoriasis in the "omic" era. Part II. Genetic, genomic and epigenetic changes in psoriasis
}

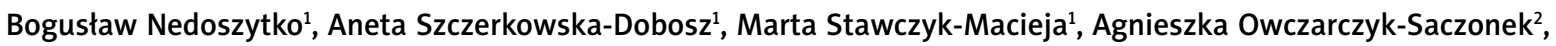 \\ Adam Reich ${ }^{3}$, Joanna Bartosińska ${ }^{4}$, Aleksandra Batycka-Baran ${ }^{5}$, Rafał Czajkowski $^{6}$, Iwona T. Dobrucki', \\ Lawrence W. Dobrucki ${ }^{7,8,9,10}$, Magdalena Górecka-Sokołowska ${ }^{6}$, Anna Janaszak-Jasiecka9 ${ }^{9}$, Leszek Kalinowski ${ }^{9,10,11}$, \\ Dorota Krasowska ${ }^{4}$, Dorota Purzycka-Bohdan ${ }^{1}$, Adrianna Radulska ${ }^{12}$, Edyta Reszka ${ }^{13}$, Dominik Samotij ${ }^{3}$, \\ Marta Sobalska-Kwapis ${ }^{14}$, Andrzej Słominski ${ }^{15}$, Radomir Słominski ${ }^{16}$, Dominik Strapagiel ${ }^{14}$, Justyna Szczęch ${ }^{3}$, \\ Michał Żmijewski ${ }^{17}$, Roman J. Nowicki ${ }^{1}$
}

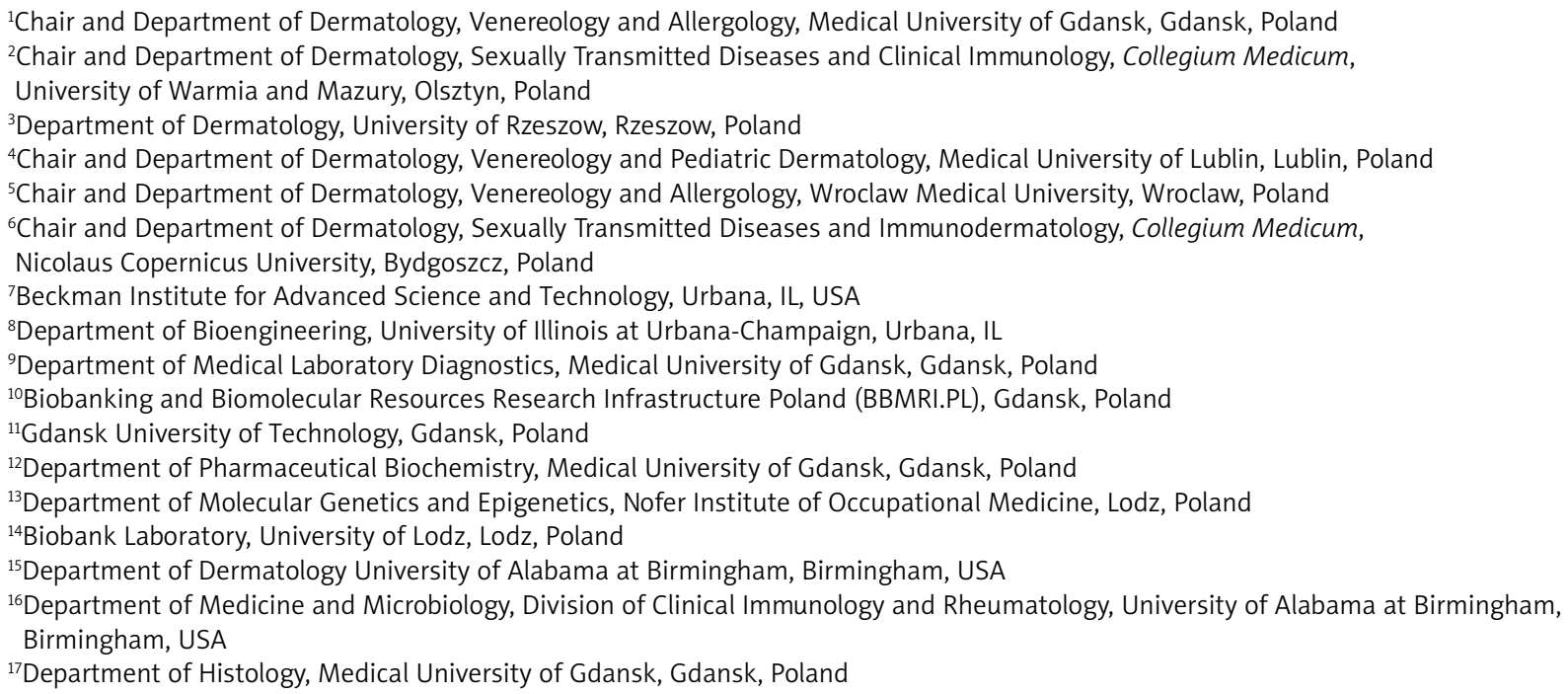

\begin{abstract}
Psoriasis is a multifactorial disease in which genetic, environmental and epigenetic factors regulating gene expression play a key role. In the "genomic era", genome-wide association studies together with target genotyping platforms performed in different ethnic populations have found more than 50 genetic susceptible markers associated with the risk of psoriasis which have been identified so far. Up till now, the strongest association with the risk of the disease has been proved for HLA-C*06 gene. The majority of other psoriasis risk SNPs are situated near the genes encoding molecules involved in adaptive and innate immunity, and skin barrier function. Many contemporary studies indicate that the epigenetic changes: histone modification, promoter methylations, long non-coding and micro-RNA hyperexpression are considered as factors contributing to psoriasis pathogenesis as they regulate abnormal keratinocyte differentiation and proliferation, aberrant keratinocytes - inflammatory cells communication, neoangiogenesis and chronic inflammation. The circulating miRNAs detected in the blood may become specific markers in the diagnosis, prognosis and response to the treatment of the disease. The inhibition of expression in selected miRNAs may be a new promising therapy option for patients with psoriasis.
\end{abstract}

Key words: psoriasis genetics, genome-wide association studies, epigenetic changes, miRNA.

Address for correspondence: Dr. Bogusław Nedoszytko, Chair and Department of Dermatology, Venereology and Allergology, Medical University of Gdansk, 17 Mariana Smoluchowskiego St, 80-214 Gdańsk, Poland, e-mail: bned@gumed.edu.pl Received: 3.04 .2020 , accepted: 6.05 .2020 . 
B. Nedoszytko, A. Szczerkowska-Dobosz, M. Stawczyk-Macieja, A. Owczarczyk-Saczonek, A. Reich, J. Bartosińska, A. Batycka-Baran, R. Czajkowski, I. T. Dobrucki, L. W. Dobrucki, M. Górecka-Sokołowska, A. Janaszak-Jasiecka,

L. Kalinowski, D. Krasowska, D. Purzycka-Bohdan, A. Radulska, E. Reszka, D. Samotij, M. Sobalska-Kwapis, A. Słominski, R. Słominski, D. Strapagiel, J. Szczęch, M. Żmijewski, R. J. Nowicki

\section{Genetics of psoriasis}

Psoriasis is a complex disease with the interaction between genes, immune system and environmental factors implicated in onset and progression of the disease. The genetic background of psoriasis is evident by the familial prevalence of the disease. A study done by Farber et al. in 1974 shows that psoriasis is more common in first- and second-degree relatives of psoriasis patients and the concordance risk of psoriasis in monozygotic twins is 2-3 times higher compared to dizygotic twins (20-73\% vs. $12.30 \%$ ) [1]. The absence of $100 \%$ concordance in monozygotic twins and not characterized in heritance pattern in families with multiple cases of the disease implies multifactorial background of the disease considering the interaction of many genes with environmental factors. The enormous development of molecular genotyping technologies, in particular genome-wide association studies (GWASs) with large case-control data sets typed, have revealed that psoriasis is strongly dependent on genomic variations and enabled the description of numerous genetic variants that are associated with

Table 1. Psoriasis susceptibility loci and candidate genes

\begin{tabular}{|c|c|c|}
\hline PSORS loci & $\begin{array}{l}\text { Chromosome } \\
\text { location }\end{array}$ & $\begin{array}{l}\text { Candidate } \\
\text { genes }\end{array}$ \\
\hline PSORS1 & $6 p 21.33$ & $H L A-C$ \\
\hline PSORS2 & $17 q 25.3$ & CARD14 \\
\hline PSORS3 & $4 q$ & $\begin{array}{c}\text { NFKB1, CFI, KIAA1109, IL2, IL21, } \\
\text { IL21-AS1, BBS12 }\end{array}$ \\
\hline PSORS4 & $1 q 21$ & $\begin{array}{c}\text { HFE2, FLG, LCE3C, LCE3B, LCE3A, } \\
\text { LCE3E, LCE2C, LCE1C, LCE1A, } \\
\text { SMCP, IVL, SPRR2C, SPRR2G, } \\
\text { LELP1, PRR9, LOR, PGLYRP3, } \\
\text { PGLYRP4, S100A9 }\end{array}$ \\
\hline PSORS5 & $3 q 21$ & SLC12A8 \\
\hline PSORS6 & $19 \mathrm{p} 13$ & BSG, SMARCA4, OR7A10 \\
\hline PSORS7 & $1 p$ & $\begin{array}{l}\text { TNFRSF9, TNFRSF1B, KAZN, } \\
\text { IGSF21, PAX7, CAPZB, IFNLR1, } \\
\text { RUNX3, AZIN2, CSMD2, OMA1, } \\
\text { IL23R, GNG12-AS1, LRRC7, AK5, } \\
\text { SPATA1, DDAH1, GBP6, KIAA1107, } \\
\text { CEPT1, DENND2D, PTPN22 }\end{array}$ \\
\hline PSORS8 & $16 q$ & $\begin{array}{c}C Y L D, N O D 2, F T O, C D H 8, S M P D 3, \\
C D H 3, I L 34, M L K L, C M I P, C D H 13, \\
\text { SLC38A8, MBTPS1, WFDC1, } \\
\text { KIAA0513 }\end{array}$ \\
\hline PSORS9 & $4 q 31-q 34$ & RNF150, DCHS2, MSMO1, SPATA4 \\
\hline PSORS10 & $18 p 11.23$ & \\
\hline PSORS11 & $5 q 31.1-q 33.1$ & RAD50, IL13, IL4, STK32A, TNIP1 \\
\hline PSORS12 & $20 q 13$ & SPATA2, RNF114, CYP24A1 \\
\hline PSORS13 & $6 q 21$ & TRAF3IP2 \\
\hline PSORS14 & $2 q 14.1$ & IL36RN \\
\hline PSORS15 & $2 q 36.1$ & AP1S3 \\
\hline
\end{tabular}

the disease. This in turn was crucial in understanding the pathogenetic pathways and molecular mechanisms that lead to psoriatic plaques. Without these discoveries, it would not be possible to introduce new, highly specific, pathogenesis-based treatments for this chronic, debilitating disease. Understanding the genetic determinants of psoriasis and putting into practice genomics-based susceptibility testing hopefully will allow to achieve the goal of personalized therapy for the disease.

\section{The history of genetic research of psoriasis}

The history of genetic research on psoriasis dates back to the early 1970s, when Russell et al. and White et al. independently observed that tissue class I compatibility antigens B37 and B57 encoded by the major histocompatibility complex (MHC) genes located on the sixth chromosome (6p21.33) may be genetic markers of psoriasis susceptibility $[2,3]$. The results of the research conducted in subsequent years among ethnically and racially different populations showed that this relationship is secondary to correlation with the HLA-Cw6 antigen and is associated with the phenomenon of non-random allele coupling in haplotypes characteristic of the MHC region - linkage disequilibrium (i.e., co-inheritance). Most reports that appeared in the following years unanimously pointed to the HLA-Cw6 antigen as a genetic marker of susceptibility to psoriasis [4-6].

\section{Linkage studies}

The early studies that shed light on the genetics of psoriasis were based on linkage studies, a statistical approach that enables the localization of disease genes to well define chromosomal regions. This method, introduced in the 1990s, uses family studies with numerous cases of psoriasis and is based on the analysis of microsatellite markers (short tandem repeats - STR), consisting of repeated, short motifs of 1-6 pairs rules. It is assumed that people with familial psoriasis have an increased probability of having the same marker located in the vicinity of the psoriasis susceptibility locus, therefore the linkage analysis technique was useful in determining areas of high risk of developing psoriasis, so-called risk intervals, and in the subsequent identification phase, genes by mapping or sequencing. Nevertheless, the feedback results should be interpreted with some caution. The restrictions about some of the conducted linkage analyses relate to the small number of studied groups of sibling pairs, the lack of phenotypic homogeneity of psoriasis in patients covered by the analysis or the demographic differences of the analyzed populations. Despite these limitations, linkage analysis identified fifteen different regions (known as psoriasis susceptibility 1-15 - PSORS1-15) that were supposed to contribute to disease susceptibility [7] (Table 1). Of these, only PSORS1 


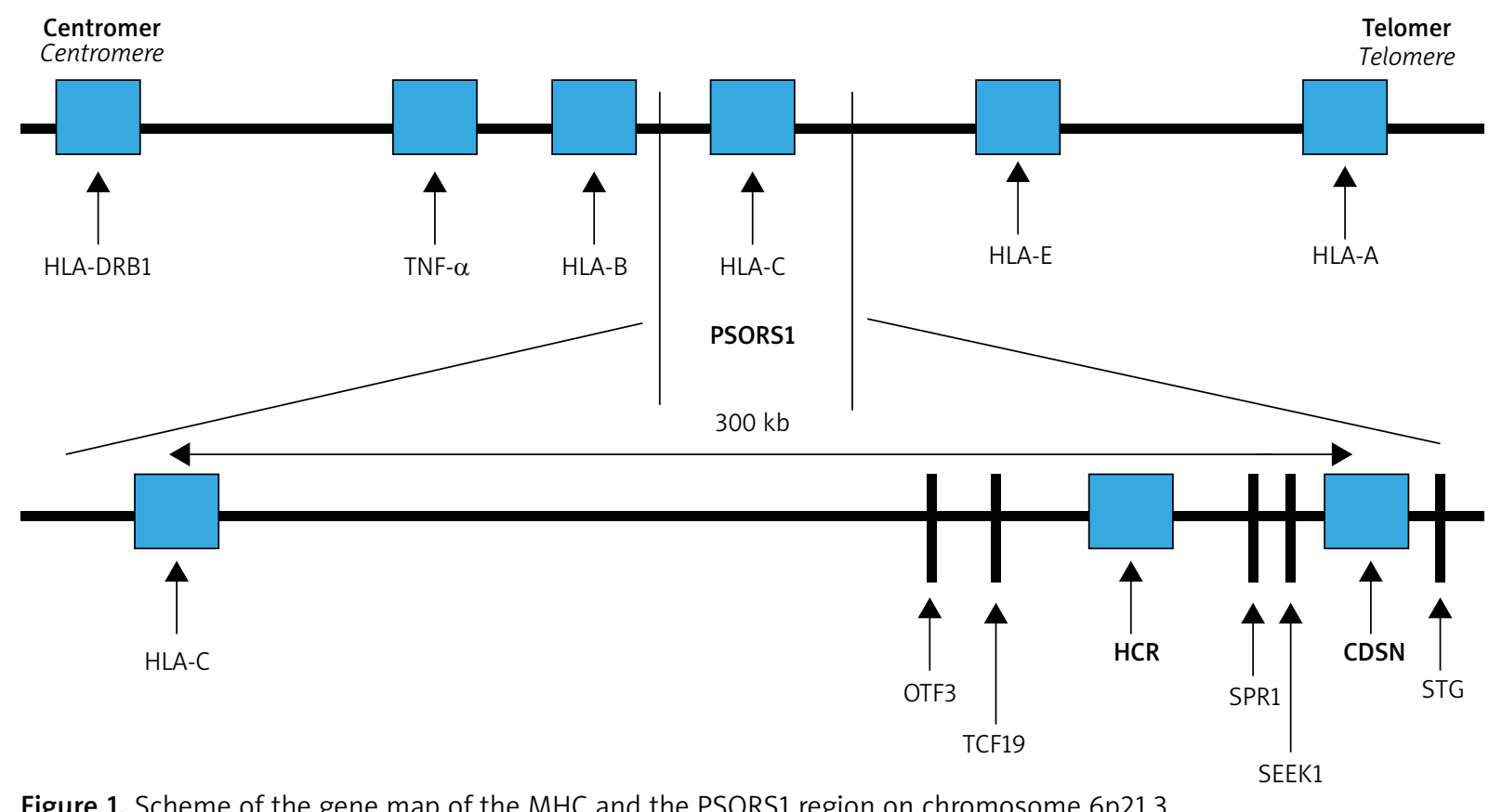

Figure 1. Scheme of the gene map of the MHC and the PSORS1 region on chromosome $6 \mathrm{p} 21.3$

was robustly validated in all examined cohorts. This led researchers to conclude that the interval harbored a major genetic determinant for the disease [8]. Weaker linkage signals at the PSORS2 and PSORS4 regions were observed in more than one dataset, suggesting that these were genuine susceptibility loci [9-13]. Linkage to the remaining PSORS regions could not be replicated in independent studies [7].

\section{PSORS1 - major susceptibility locus in psoriasis}

The strongest correlation with psoriasis maps to the PSORS1 locus. This region covers about $300 \mathrm{~kb}$ (thousands of base pairs) from the corneodesmosin (CDSN) gene to HLA-C within the MHC on chromosome 6 (Figure 1). The SNPs detected at least nine non-HLA-C genes located telomerically to HLA-C locus: HCR, CDSN, POU5F1, TCF19, HCG27, PSORS1C3, PSORS1C2 (SPR1), PSORS1C1 (SEEK1) and STG. Of these, three: HLA-C, CCHCR1 and CDSN were highly polymorphic and harbored coding variants that were significantly associated with psoriasis [8]. Ultimately, the results of extensive multicenter studies published by Nair et al. indicated $\mathrm{HLA}-\mathrm{CW}^{\star} \mathrm{O} 6$ as the main allele of psoriasis susceptibility in PSORS1, accounting for about $30-50 \%$ of the genetic involvement to the disease [8]. In most studies of the European populations, the HLA$\mathrm{CW}^{\star} 06$ allele occurs in 55-80\% of patients with early onset psoriasis, while in a healthy population it usually does not exceed $20 \%$ increasing the risk of psoriasis 9 to 23-fold [14]. Moreover HLA-CW*06 correlates with earlier onset, positive family history and more severe disease course. It has also been shown that in patients homozygous for the $\mathrm{HLA}-C W^{\star} 06$ allele, the risk of developing psoriasis is 2.5 times higher compared to heterozygous ones [14]. HLA-CW*06 positive individuals are more likely to have a guttate psoriasis preceded by an upper respiratory streptococcal infection.

Several hypotheses explain the relationship between HLA-C as an antigen presentation molecule and the molecular pathogenesis of psoriasis. HLA-C is a very likely candidate gene because it encodes $\mathrm{MHC}$ class I molecule contributing to the immunological response by participating in the presentation of short peptide non-self antigens to ab TCRs CD8+ T cells and in that way activating natural killer cells. Presuming the ability of HLA-C to present antigens and basing on the hypothesis that the lesional CD8 ${ }^{+} T$ cells react against keratinocytes, it was assumed that HLA CW*06 has a high ability to bind suggested psoriatic autoantigens: a specific melanocyte auto-antigen ADAMTSL5 (peptide from ADAMTS-like protein 5), a disintegrin and metalloprotease domain containing thrombospondin type 1 motif-like to $C D 8^{+} T$ cells, which activates IL-17 production by CD8 T and LL-37 (a 37 amino acid C-terminal cleavage product of the antimicrobial peptide, cathelicidin) produced by keratinocytes, activating both CD8+ cytotoxic T cells and CD4+ T helper cells in psoriasis [15-17]. LL37-specific T cells can be found in lesional skin or in the blood of patients with psoriasis, where they correlate with disease activity. Both autoantigens are recognized by $T$ cells by being presented by $\mathrm{HLA}-\mathrm{CW}^{*} 06$ [15-18].

\section{The PSORS2 locus}

PSORS2 region within $17 q 25.3$ chromosome was identified on the basis of linkage studies in two ethni- 
cally different multigenerational families (Caucasian and Asian) with numerous cases of psoriasis [19]. This area includes the CARD family which encompasses scaffolding proteins that activate nuclear factor- $\kappa \mathrm{B}(\mathrm{NF}-\kappa \mathrm{B})$ that is highly expressed in keratinocytes. People with a gainof-function mutation in the gene encoding the protein CARD14 (caspase recruitment domain-containing protein 14, also called CARMA2 or BIMP2) have been shown to have increased the risk of psoriasis, psoriatic arthritis, and familial pityriasis rubra pilaris. The NF- $\kappa$ B signaling pathway plays a role in stimulating the inflammatory production of interkeukin (IL) 17 and tumor necrosis factor $\alpha$ (TNF- $\alpha)$ - pro-inflammatory cytokines [20]. What is more, GWAS research has uncovered common alleles in case-control studies, which shows that CARD14 contains both common variants with low-effect and rare but highpenetration mutations [21].

\section{The PSORS4 locus}

The PSORS4 region maps to chromosome 1q21, where it spans the Epidermal Differentiation Complex (EDC) with multiple genes responsible for epidermal development and maturation. EDC genes are activated in the final phases of keratinocyte differentiation and include, among others: loricrin, involucrin, filaggrin, late cornified envelope proteins (LCE) genes. Within the LCE region, three gene families are distinguished: LCE1, LCE2 and LCE3. De Cid et al. first demonstrated the association with psoriasis of the LCE complex containing a reduced number of copies of the $L C E 3 C$ and $L C E 3 B$ genes, while what is worth emphasizing - the LCE3C/LCE3B deletion was not demonstrated in patients with atopic dermatitis [22-24]. This observation, together with the results of other reports indicates that there is no mutation in the filaggrin gene in psoriasis, which indicates that these two chronic inflammatory skin diseases are characterized by a different defect of the epidermal barrier.

\section{Genetic variants in different psoriasis phenotypes}

$H L A-C W^{*} 06$ is currently considered as a genetic variant affecting the chronic plaque psoriasis phenotype. This allele is more common in patients with psoriasis beginning at a young age with a positive family history, in guttate psoriasis, in more severe forms of the disease $[6,14,25]$. In individuals with the guttate form, psoriasis is often initiated with preceding streptococcal sore throat that leads to believe that in $\mathrm{HLA}-C W^{*} 06$ risk allele individuals infectious pathogens are probably the initiating triggers. Recent studies have shed light on the genetic determinants of rare forms of psoriasis - a group of severe skin disorders, with systemic upset characterized by eruptions of neutrophil-filled pustules: pustulosis palmoplantaris (PPP) and generalized pustular psoriasis (GPP).
Pustular eruption may be the only manifestation of the disease or may occur concurrently with chronic plaque psoriasis. Remarkable clinical and histopathological differences as well as a distinct response to therapy indicate that plaque and pustular psoriasis may be entities with different etiology. Palmoplantar pustulosis shows no relationship with any of the three candidate genes at PSORS1 locus (HLA-CW*6, HCR*WWCC, and CDSN*5), and some authors suggest it to be a phenotypically (affects females in the perimenopausal period as well as cigarette smokers) and genetically distinct disorder [26, 27]. In terms of GPP in 2011, two groups of researchers independently described a mutation in the IL36RN gene [28, 29]. IL36RN belongs to the IL-1 cytokine family, involved in innate immunological response. IL36RN encodes for an interleukin 36 receptor antagonist molecule that inhibits IL-36 proinflammatory activity. The mutation of the IL-36 loss-of-function gene causes an uncontrolled increase in the proinflammatory IL-36 signaling pathway, with subsequent activation of IL-8, and IL-6. Biallelic mutations in IL36RN gene have been described in $21-41 \%$ of the Caucasian and Asian patients with GPP [30]. Two additional genetic variants have been also described in GPP and PPP - CARD14 and APIS3 (encoding a subunit of the adaptor protein 1 complex), although latest studies by Mossner et al. suggest that AP1S3 and CARD14 variants have a much lower impact in GPP than variants in IL36RN [31]. Pustular psoriasis often coexists with chronic plaque psoriasis, therefore it is assumed that also in this common form of the disease, the disturbance of the IL-36 signaling pathway plays a role. Chronic plaque psoriasis has been shown to be correlated with over activation of IL-36 and IL-36 blockade has a significant anti-inflammatory activity. Thus, the hypothesis that the IL-36 signaling pathway may be a therapeutic target not only in pustular psoriasis, but also in chronic plaque psoriasis is justified [32-34].

\section{Genome-wide association studies in psoriasis}

At the beginning of the century, a huge progress in genotyping technologies was observed. It led to the introduction of GWAS, where large case-control datasets are typed at hundreds of thousands of single nucleotide polymorphisms (SNPS). The success of GWAS resulted in developing target genotyping platforms, such as ImmunoChip referring to the SNPs previously associated with immune-mediated disorders and the Exome-wide chip enabling analyzing genetic markers within coding regions. Up till now, genome-wide association studies together with target genotyping platforms performed in different ethnic populations, have identified approximately 50 genetic susceptible markers associated with the risk of psoriasis at genome-wide significance $p<5 \times 10^{-8}$ [35-47]. The summary of non-MHC psoriasis genetic risk markers identified by GWAS at genome- 


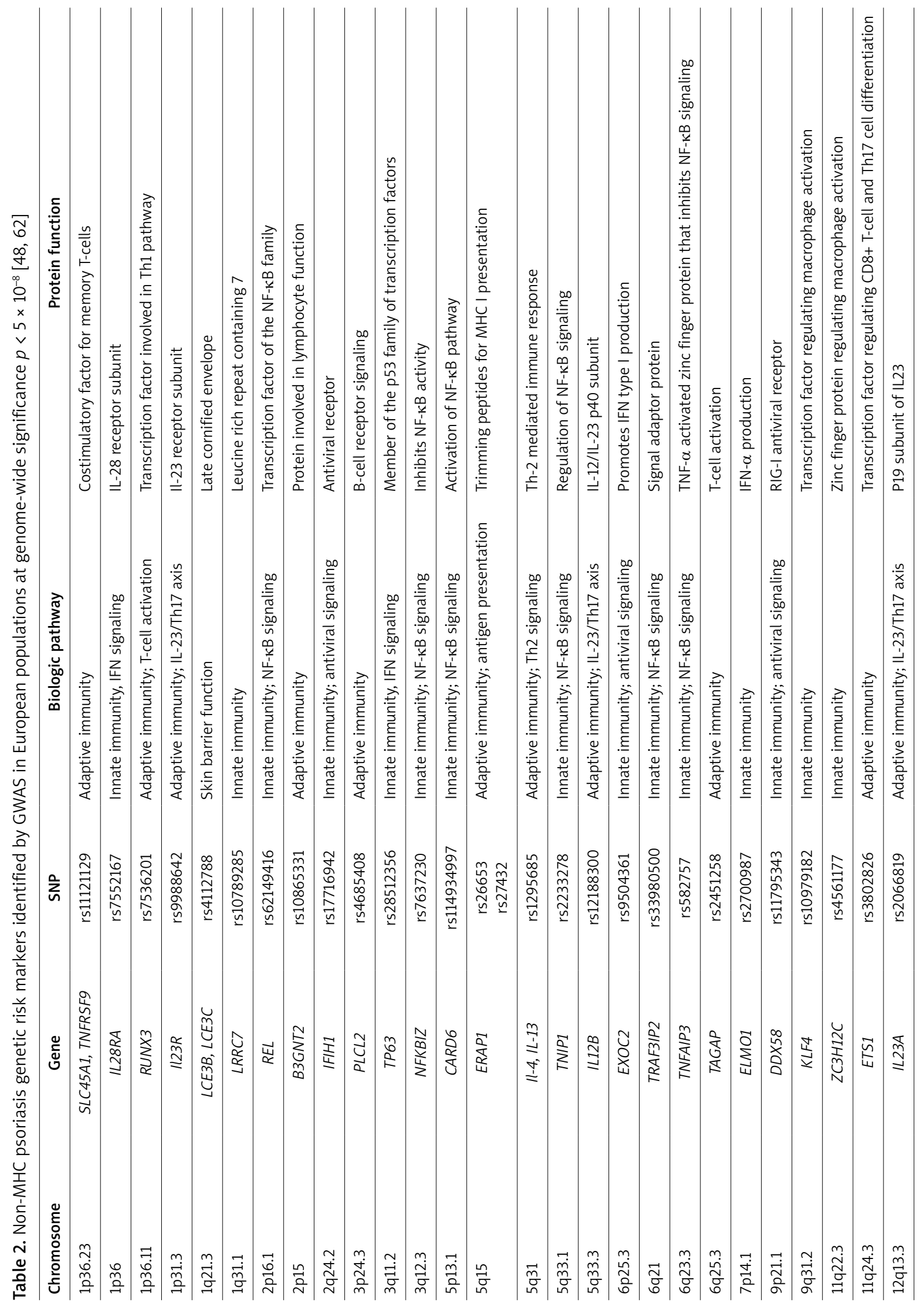




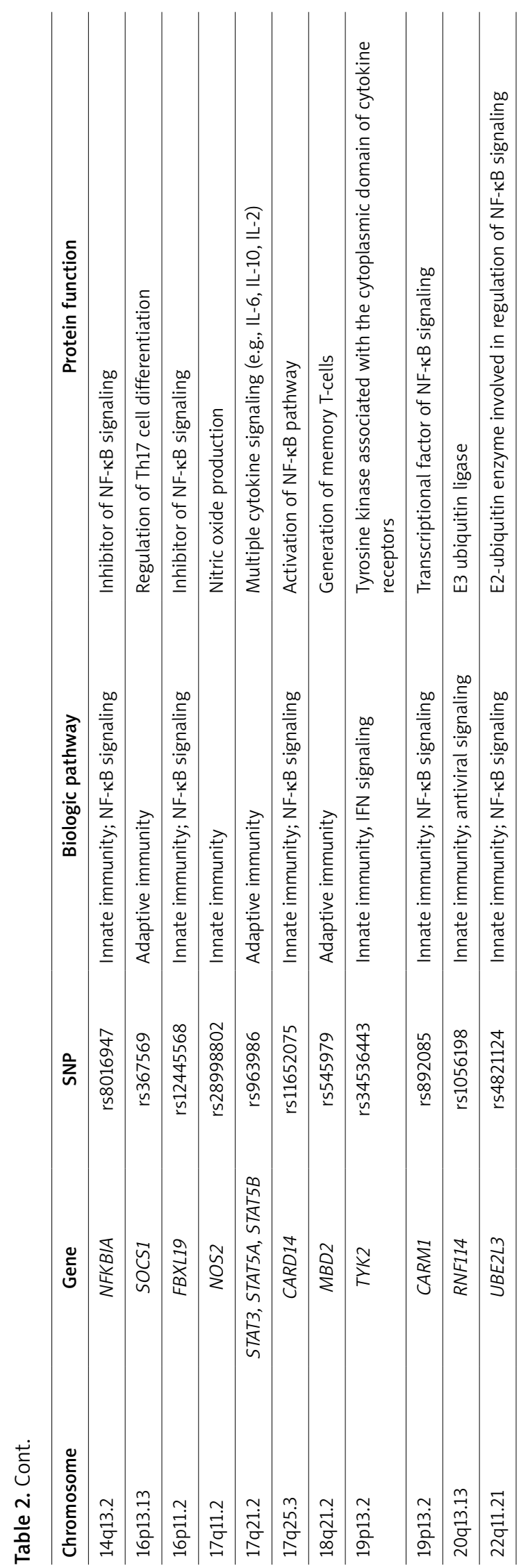

wide significance $p<5 \times 10^{-8}$ in European populations has been presented in Table $2[48,49]$.

The majority of psoriasis risk SNPs determined by GWAS technique is situated near the genes encoding molecules involved in adaptive immunity, innate immunity and skin barrier function. Up till now, the region involving MHC class I on chromosome 6p21 is the genetic locus associated with the greatest risk of psoriasis, and is called PSORS1. Among genes identified in the locus, HLA$C^{*} 06$ presents the strongest association with the disease, that has been proved in different ethnic populations.

HLA-Cw6 encodes a major histocompatibility complex I (MHCl) allele critical for CD8+ T-cells priming and subsequent cytolytic targeting of cells [50-55].

Outside the MHC region, numerous SNPs within the endoplasmic reticulum aminopeptidase 1 (ERAP1) gene have been proven to have an effect on genetic predisposition to psoriasis [56]. ERAP1 encodes the protein involved in the process of $\mathrm{N}$-terminal trimming of antigens allowing their presentation in the context of MHC class I that results in the activation of CD8+ lymphocytes. The association of ERAP1 with the risk of psoriasis has been also confirmed in the population of northern Poland in the rs26653 marker [57]. These results show the evidence of the primary role of the adaptive immune system in the pathogenesis of psoriasis.

Numerous SNPs associated with the risk of psoriasis identified by GWAS proved the role of the innate immune system in the pathogenesis of the disease. In general, these can be divided into genetic markers involved in: effector T-cell function and differentiation (ETS1, RUNX3, TNFRSF9, MBD2, IRF4), type I interferon and cytokine signaling (ELMO1, TYK2, SOCS1, IFIH1/MDA5, RNF114, IRF4, RIG1/DDX58, IFNLR1/IL28RA, IFNGR2), and regulation of NF-KB associated inflammatory signaling pathways (TNFAIP3, TNIP1, TYK2, REL, NFKBIA, CARD14, CARM1, UBE2L3, FBXL19). To continue, the discovery of genetic factors implicated in psoriasis involved in IL-23/L-17 axis (IL23R, IL12B, IL12RB, IL23A, IL23R, TYK2, STAT3, STAT5A/B, SOCS1, ETS1, TRAF3IP2, KLF4, IF3) provided many insights into interactions between innate and adaptive immune responses in the spectrum of immunological disturbances of the disease [58].

Independent groups of researchers showed the association of late cornified envelope genes involved in the skin barrier functioning with psoriasis. Numerous observations in both European and Chinese populations have proven a common 30-kb deletion in $\angle C E 3 B$ and $L C E 3 C$ genes (LCE3C_LCE3B-del) to predispose to psoriasis [21, $47,59]$. The loss of this fragment is considered to be responsible for the dysfunction of reparative mechanisms of the skin barrier after mechanic trauma [60].

Although the GWAS findings provided many insights into specific genetic predisposition, immunological mechanisms and skin barrier function that may play role in the pathogenesis of psoriasis, they still explain less than one 
third of the disease genetic heritability in the European populations [21, 61]. This phenomenon is known as missing heritability [52]. In the context of complex disorders, it may be explained by existence of gene-gene, gene-environmental interactions or regulation of gene expression by epigenetic mechanisms [49, 62]. To continue, GWAS analyzes the independent effect of each SNP that can be insufficient to account for missing heritability. What is more, based on the GWAS results, the minority of known genetic psoriasis risk loci span a single gene, whereas the majority associates with multiple transcripts or noncoding regions. This results in limitations in explaining certain biological pathways as well as determination of specific cells mediating pathways involved in the pathogenesis of psoriasis. Finally, within an increasing role of next-generation sequencing (NGS) techniques as well as the development of new statistical methods it is likely that more genetic signals will be discovered.

\section{Epigenetic changes in psoriasis}

Epigenome is a set of chemical modifications of DNA and histone proteins which cause the changes to the chromatin structure and influence the activation of transcription process of certain genes, and then the process of translating new mRNA on the polypeptide chain. Epigenetic changes do not change the genetic code, i.e. DNA sequence, but rather the expression of certain genes.

Epigenetic processes can regulate the gene expression at three different levels:

1. The methylation or demethylation of cytosine in gene promoter sequences. Methylation/hydroxymethylation of a promoter causes the gene to become inactive and not susceptible to transcription. In contrast, demethylation of a promoter causes the gene to be susceptible to transcription so that the protein which the gene codes can be produced.

2. The modification of histones chemically (methylation, acetylation, phosphorylation, sumoylation, ubiquitylation) which leads to changing the structure of cell nucleus chromatin. As a result, the density and availability for enzyme complexes taking part in the transcription process may change. Histone acetylation and $\mathrm{H} 3$ lysine 4 trimethylation are associated with active genes transcription and open chromatin structure, while trimethylation of $\mathrm{H} 3 \mathrm{~K} 9$ and $\mathrm{H} 3 \mathrm{~K} 27$ are associated with transcriptional repression and closed chromatin structure.

3. By the non-coding proteins of RNA particles: long noncoding RNAs (InRNA), micro-RNAs (miRNAs), small interfering RNAs (siRNAs) and Pivi-interacting RNAs (piRNAs). Recent studies have demonstrated that these RNAs are capable to regulate gene expression at the transcriptional, post transcriptional and epigenetic level. For example micro-RNAs which join specifically to the complementary mRNA particles, influence its sta- bility and miRNA/mRNA complex cannot join the ribosome, in consequence is degraded in cytoplasm, which leads to inhibition of gene expression by blocking the process of translation [63-75].

\section{Epigenetic changes in psoriasis}

Epigenetic modifications are considered essential in the pathogenesis of psoriasis as they account for keratinocyte differentiation and proliferation, resulting in aberrant increases in epidermal thickness, abnormal keratinocytes inflammatory cells communication, neoangiogenesis and chronic inflammation [63-68].

Epigenetic changes also play a fundamental role in the processes of differentiation of the CD 4 (+) T lymphocyte subpopulations that are so important for the pathogenesis of psoriasis [70]. Figure 2 illustrates epigenetic changes in the promoter regions of selected genes and in histones observed in the time of differentiation of CD4(+) T cell subpopulations.

\section{Histone modification in psoriasis}

Zhang et al. are the first authors who have found that global histone $\mathrm{H} 4$ hypoacetylation was observed in PBMCs (peripheral monoclonal blood cells) from psoriasis vulgaris patients [72]. There was a negative correlation between the degree of histone $\mathrm{H} 4$ acetylation and disease activity in patients as measured by PASI. Global levels of histone $\mathrm{H} 3$ acetylation, H3K4/H3K27 lysine methylation did not significantly differ between psoriatic patients and controls. mRNA levels of P300, CBP and SIRT1 were significantly reduced in PBMCs from patients with psoriasis vulgaris compared with healthy controls, while mRNA expression levels of protein involved in histone modifications: histone deacetylase 1 (HDAC1), histone-lysine N-methyltransferase (SUV39H1) and histone-ILysine N-methyltransferase EZH2 (enhancer of zeste homolog 2) were significantly increased in psoriatic patients, which allowed the authors to conclude that histone modifications are aberrant in the PBMCs of psoriasis vulgaris patients.

Ovejero-Benito et al. [71] studied epigenetic changes in responders and non-responders to biological drugs (ustekinumab, secukinumab, adalimumab, ixekizumab). Significant changes in methylated lysine 27 in histone 27 (H3K27) and methylated lysine in histone 3 (H3K4) in patients with psoriatic arthritis were found between responders and non-responders. Authors suggest that H3K27 and H3K4 methylation may contribute to patients' response to biological treatment in psoriasis [71].

\section{DNA methylation changes observed in psoriatic skin}

The methylation of cytosine residues is the most frequently observed post-replication change in DNA. 


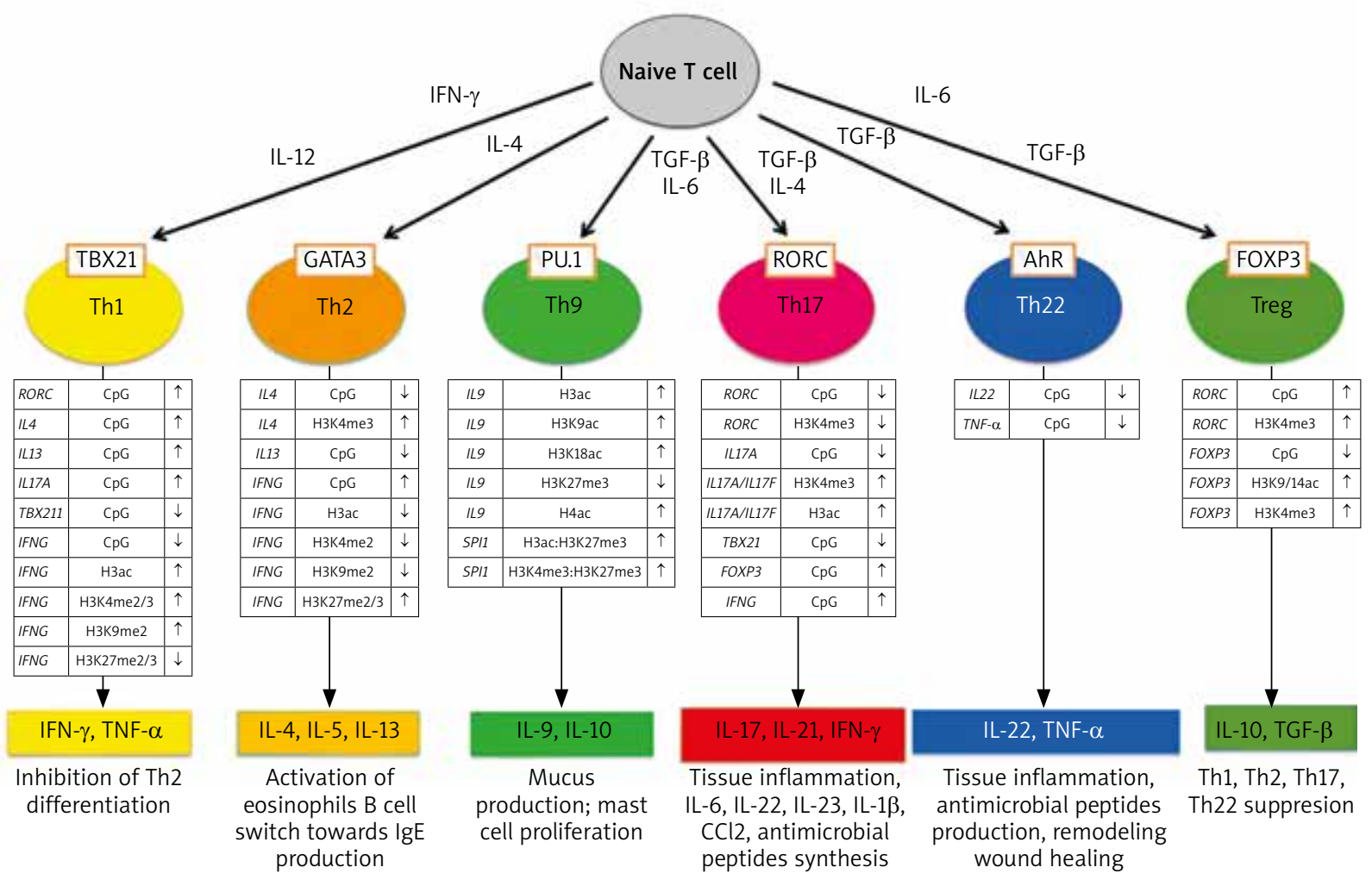

Figure 2. Epigenetic modifications of DNA and histones in the development of different set of CD4 (+) T cells (from Potaczek et al. 2017 modified [70])

It is estimated that in mammals, $60-70 \%$ of cytosines are constantly methylated. Particularly rich in cytosine residues, referred to as $C p G$ sites, are the promoter regions of genes, i.e. their regulatory sites that precede the initiation sites of transcription. Specific proteins, transcription factors that regulate the transcriptional process are added to the promoter regions. Methylation of cytosine in the gene promoter prevents the incorporation of transcription factors and transcriptases and, as a result, blocks the process of its expression. Demethylation activates the promoter and allows the gene transcription process to begin. DNA methylation occurs with the participation of specific DNA methyltransferases (DNMTs) whereas DNA demethylation is catalyzed by tet methylcytosine dioxygenases 1-3 (TET - ten-eleven translocation gene protein) enzymes. Cells with a similar function show similar gene methylation patterns [63-67, 75-78].

Zhang et al. observed that the peripheral blood cells of psoriasis patients have an increased expression of DNA methyltransferases (DNMTs) as compared to healthy controls [77]. In the skin and epidermis, the hypermethylation of the promoter gene involved in cell cycle regulation, p16INK4a (cyclin-dependent kinase 4 inhibitor A) was observed and as a result, there has been a reduction in the following genes: P53, p14ARF, and ID4 (inhibitor of differentiation 4). The consequence of this is the inhibition of cellular differentiation and parakeratosis [77-81].
The pioneer study of global epigenetic of psoriasis was published in 2012. Authors analyzed the methylation status of more than 27,000 CpG sites in skin samples from lesional and non-lesional skin of patients with psoriasis and skin of healthy controls. 1,100 differentially methylated CpG sites were detected between psoriatic and control skin. Twelve CpG sites mapped to the epidermal differentiation complex (S100 Calcium Binding Proteins: S100A3, S100A5, S100A7, S100A12, sperm mitochondria associated cysteine rich protein - SMCP, small proline rich proteins: SPRR2A, SPRR2D, SPRR2E, late cornified envelope protein 3A - LCE3A). The most extreme change was found in cg16139316, which lies upstream from S100A9. There was a decrease in methylation at these sites, and they mapped close to genes that are highly upregulated in psoriasis. The investigators analyzed 50 of the top differentially methylated sites to separate/differentiate skin from patients with psoriasis from that of controls. Interestingly, with anti-tumor necrosis factor treatment, these methylation changes in patients reverted back to baseline [76].

Chandra et al. [75] used the genome-wide DNA methylation profiling and have found that differentially methylated genes in psoriatic skin regions were associated with psoriasis. Top differentially methylated genes overlapped with PSORS regions including S100A9, SELENBP1, CARD14, KAZN and PTPN22 showed an inverse correla- 
tion between methylation and gene expression. The authors made an interesting observation that in psoriatic skin with Munro microabscess, there is an increased expression of differentially methylated genes, responsible for the chemotaxis of neutrophils forming abscesses [75].

\section{Non-coding RNA and their role in psoriasis}

Genome-wide association studies have identified many psoriasis-associated genetic loci in the Caucasian population $[82,83]$. However, most genome-wide association study signals lie within non-coding regions of the human genome [63-66, 84, 85]. The thesis is well documented today that non-protein coding DNA regions plays the role in genetic and epigenetic of many diseases and included account "missing heritability".

Two main classes of non-coding RNA, plays the role in pathogenesis of psoriasis: long non-coding RNA (IncRNA) and micro RNA (miRNAs) [64-66, 68, 85-94].

\section{Long non-coding RNA in psoriasis}

Long non-coding RNA (IncRNA), defined as non-protein coding RNA transcripts longer than 200 nucleotides, are acting as key regulators of diverse cellular processes. Three different groups of IncRNA can be categorized, namely, natural antisense transcripts (NATS), intronic RNA (IncRNAs), and long intergenic (intervening) noncoding RNA (lincRNAs). IncRNA are involved in epigenetic silencing, splicing process regulation, translation control, regulating the apoptosis and cell cycle control. Moreover, the expression levels of various IncRNA are closely related to epidermal differentiation and immunoregulation [85-93]. There are many examples illustrating that IncRNAs are also involved in regulation of a variety of skin pathological conditions including skin cancer, wound healing and psoriasis [85-88].

Tsoi et al. analyzed the expression of IncRNA in involved and uninvolved psoriatic skin and detected 2942 previously annotated and 1080 novel IncRNAs, which were expected to be skin-specific. Their results indicated that many IncRNAs, in particular those that were differentially expressed, were co-expressed with genes involved in immune-related functions. Additionally, novel IncRNAs were enriched in the epidermal differentiation complex. They also identified distinct tissue-specific expression patterns and epigenetic profiles for novel IncRNAs. Altogether, these results indicate that great deals of IncRNAs are involved in the immune pathogenesis of psoriasis [87, 91].

Two important IncRNAs are involved in the control of epidermal differentiation: ANCR and TINCR. ANCR (Antidifferentiation non-coding RNA) acts as a negative regulator of epidermal differentiation. Loss of ANCR in progenitor cells rapidly induces the differentiation program; therefore, it is needed to suppress premature differen- tiation in the basal layer of the epidermis. In contrast, TINCR (terminal differentiation-induced non-coding RNA) is highly expressed in the differentiated epidermal layer and promotes keratinocyte differentiation [88].

A study of Sonkoly et al. indicated that long noncoding RNA - PRINS (psoriasis-associated RNA induced by stress), is elevated in non-lesional skin areas in patients with psoriasis while it is decreased in the psoriatic plaques. PRINS contributes to psoriasis via the downregulation of G1P3, a gene coding protein with anti-apoptotic effects in keratinocytes [89].

Recently, Qiao et al. [93] have suggested that the other cytoplasmic IncRNA - Msh homeobox 2 pseudogene 1 (MSX2P1) was upregulated in psoriatic lesions compared with normal healthy skin tissues, human immortalized keratinocyte cells and normal human epidermal keratinocyte cells. LncRNA MSX2P1 facilitated the progression and growth of IL-22-stimulated keratinocytes by serving as an endogenous sponge directly binding to miR-6731-5p and activating S100A7. Authors speculate that the biological network of MSX2P1-miR-6731-5p-S100A7 might be a potential novel therapeutic target for the future treatment of psoriasis [93].

\section{The role of micro-RNAs in psoriasis}

Micro-RNAs (miR) are-small biological molecules that regulate the expression of over $30 \%$ of human genes at a post-transcriptional level. These are non-coding RNA molecules with a length of 22-25 base pairs, capable of negatively modulating gene expression by binding to the 3' untranslated region (UTR) of target messenger RNAs (mRNAs). The resulting complex undergoes degradation in the cytoplasm and, as a result, the translation process is blocked and the gene product is not produced in the cell. It is estimated that miRNA codes $1-3 \%$ of genes in the human genome [64-69].

The study of the miRNA expression profile was focused after evidence suggested that epigenetic mechanisms may have an influence on DNA outside of promoter and structural DNA genetic regions. About $60 \%$ of human mRNAs involved in the coding of cell proteins are regulated by miRNAs and more than 1800 miRNAs were identified, which indicates that miRNAs are capable of regulating almost all living processes. In this way, epigenetic factors can affect the transcriptional regulation of mRNAs involved in cell proliferation, migration, differentiation or inflammation [64-69, 93-95].

miRNAs play the role in the processes of apoptosis, cell proliferation, morphogenesis and differentiation of cells, metabolism regulation, and signal transduction in the cell. One type of miRNAs can block the functions of many different genes, also one gene can be blocked by different types of miRNAs. These molecules act in the interior of the cells in which they are produced, but they can also be secreted into body fluids such as plasma, tis- 
B. Nedoszytko, A. Szczerkowska-Dobosz, M. Stawczyk-Macieja, A. Owczarczyk-Saczonek, A. Reich, J. Bartosińska, A. Batycka-Baran, R. Czajkowski, I. T. Dobrucki, L. W. Dobrucki, M. Górecka-Sokołowska, A. Janaszak-Jasiecka,

L. Kalinowski, D. Krasowska, D. Purzycka-Bohdan, A. Radulska, E. Reszka, D. Samotij, M. Sobalska-Kwapis, A. Słominski, R. Słominski, D. Strapagiel, J. Szczęch, M. Żmijewski, R. J. Nowicki

sue fluid, milk and urine. They are protected by the fragments of cell membranes (exosomes) or by combination with high-density lipoproteins from enzymatic degradation in the plasma. The miRNAs contained in exosomes secreted by the cell can be used in a cell-to-cell communication. They can penetrate into the interior of neighboring cells and modify the expression of genes in them. It has been shown that the miRNAs contained in milk may modulate the functions of the newborn's immune system, favoring the formation of regulatory lymphocytes Treg [68, 69, 85, 93-95].

Most of the studies of miRNAs in association with psoriasis address the plaque-type variant and so far, more than 250 miRNAs are aberrantly expressed in psoriatic skin. Majority of miRNAs are upregulated in the psoriatic skin, only a small number of them are downregulated [69, 96-105].

Some miRNAs deregulated in psoriatic skin and their function are listed in Table 3 [106-138].

Through the regulation of their multiple target genes, miRNAs in psoriasis regulate the development of inflammatory cell subsets and have a significant impact on the magnitude of inflammatory responses. miRNAs can regulate differentiation, proliferation and cytokine response of keratinocytes, activation and survival of $T$ cells and the crosstalk between immunocytes and keratinocytes through the regulation of chemokine and cytokine production [63-69, 93-96].
Figure 3 illustrates the role of selected miRNAs in the pathogenesis of psoriasis.

The most upregulated miRNAs in the psoriatic skin are skin-specific (miR)-203, hematopoietic-specific miRNAs: miR-142-3p and miR-223/223, angiogenic miRNAs: miR-21, miR-378, miR-100, miR-31, miR-21, miR-210, and proinflammatory miR-155 [64, 69, 93-101, 107].

miR-203 is a skin-specific miRNA, which is exclusively overexpressed in psoriatic keratinocytes and is involved in angiogenesis and keratinocyte differentiation. Their target genes are: SOCS-3, SOCS-6, p63, TNF- $\alpha$, IL-8 and IL-24. SOCS3 (suppressor of cytokine signalling3) is a negative regulator of STAT3 pathways. Increased expression of miR203 leads to decreased SOCS3 levels in psoriatic skin, which may consequently result in sustained activation of the STAT3 signaling pathways. STAT3activated transcription of EGFR, IL-6, TGF- $\beta$ genes, blocks apoptosis, favors cell proliferation and survival and promote angiogenesis [69].

Additionally, in normal human keratinocytes, the increased miR-203 is reported to be induced by combinations of proinflammatory cytokines, such as IL-1 $\alpha$, IL-17A, IL-6, and TNF- $\alpha$, which coupled with a critical role of miR203 in epithelial differentiation, suggesting that miR-203 is crucially implicated in the hyperproliferative phenotype of psoriatic lesions $[69,110,111,125,138,139]$.

miR-155 plays an important role in many processes including cell growth and proliferation. By decreasing

Table 3. Changes in the microRNA expression observed in psoriatic skin and peripheral blood cells

\begin{tabular}{|c|c|c|c|c|}
\hline miRNA & Target genes & Tissue/cell & Process & References \\
\hline$\uparrow \mathrm{mR}-31$ & Ppp6c, FIH-1, STK4O & Skin/PBMC & $\begin{array}{l}\text { G1/S phase regulator, regulation } \\
\text { NF- } \mathrm{B} \text { B activity, } \uparrow \text { Kc differentiation } \\
\text { and proliferation, } \mathrm{T} \text { cell activation, } \\
\text { angiogenesis, and leukocyte migration } \\
\text { to the skin } \uparrow \text { inflammation }\end{array}$ & $\begin{array}{c}69,102,103,105,118 \\
119,136\end{array}$ \\
\hline$\uparrow \operatorname{miR}-203$ & $\begin{array}{l}\text { SOCS-3, SOCS-6, p63, } \\
\text { TNF } \alpha, \text { IL8, IL24 }\end{array}$ & Skin & $\begin{array}{l}\text { STAT3 signaling, } \uparrow \mathrm{Kc} \text { differentiation } \\
\text { and proliferation, } \uparrow \text { inflammation }\end{array}$ & $69,110,111,125,137,138$ \\
\hline$\downarrow$ miR-99a & $I G F-1 R$ & Skin & $\uparrow$ Kc differentiation and $\downarrow$ proliferation & $104,119,125$ \\
\hline$\downarrow$ miR125b & $\begin{array}{c}\text { FGFR-2, TNF } \alpha, P 63 \\
\text { NOTCH1 }\end{array}$ & Skin & $\uparrow$ Kc differentiation and $\downarrow$ proliferation & $69,103,120,128$ \\
\hline$\uparrow \operatorname{miR}-21$ & $\begin{array}{l}\text { TIMP3, TM1, ODCD4, PTEN, } \\
\text { IL12A, RECK, RTN4, NF1B }\end{array}$ & Skin, PBMC & $\begin{array}{l}\uparrow \text { Kc differentiation and proliferation, } \\
\mathrm{T} \text { cell activation, } \uparrow \mathrm{TNF}-\alpha, \uparrow \text { inflammation }\end{array}$ & $\begin{array}{c}69,103-105,118,119 \\
122,138\end{array}$ \\
\hline$\uparrow \operatorname{miR}-135 b$ & COL4A3 & Skin & Kc differentiation and proliferation & $1103,119,126$ \\
\hline$\uparrow \mathrm{miR} 146 \mathrm{a}$ & IRAK, TRAF6, EGFR & Skin/PBMC & $\begin{array}{l}\text { Hematopoiesis, inflammation, } \\
\text { keratinocyte proliferation }\end{array}$ & $69,103-105,119,136$ \\
\hline$\uparrow \operatorname{miR}-155$ & $\downarrow C T L A-4$ & Skin & Inflammation, $\downarrow$ Treg function & $104,114,119$ \\
\hline$\uparrow \operatorname{miR}-210$ & $\downarrow$ FOXP3 & PBMCs & $\begin{array}{l}\downarrow \text { Treg activation, } \uparrow \text { differentiation of Th1 } \\
\text { and Th17, } \downarrow \text { Th2 differentiation }\end{array}$ & 115 \\
\hline 个 miR-184 & AGO2 & Skin & $\begin{array}{l}\text { Regulation of posttranscriptional } \\
\text { modification of mRNA and miRNA } \\
\text { biogenesis via the miRISC complex }\end{array}$ & 124 \\
\hline$\uparrow \operatorname{miR} 221 / 222$ & $\downarrow T I M P 3, c-K I T, P 53$ & Skin & Kc and immune cells proliferation & 118,136 \\
\hline$\uparrow \operatorname{miR}-424$ & MEK1, cyclin E1 & Skin & Kc differentiation and proliferation & 104,125 \\
\hline
\end{tabular}


Inflammatory skin microenvironment

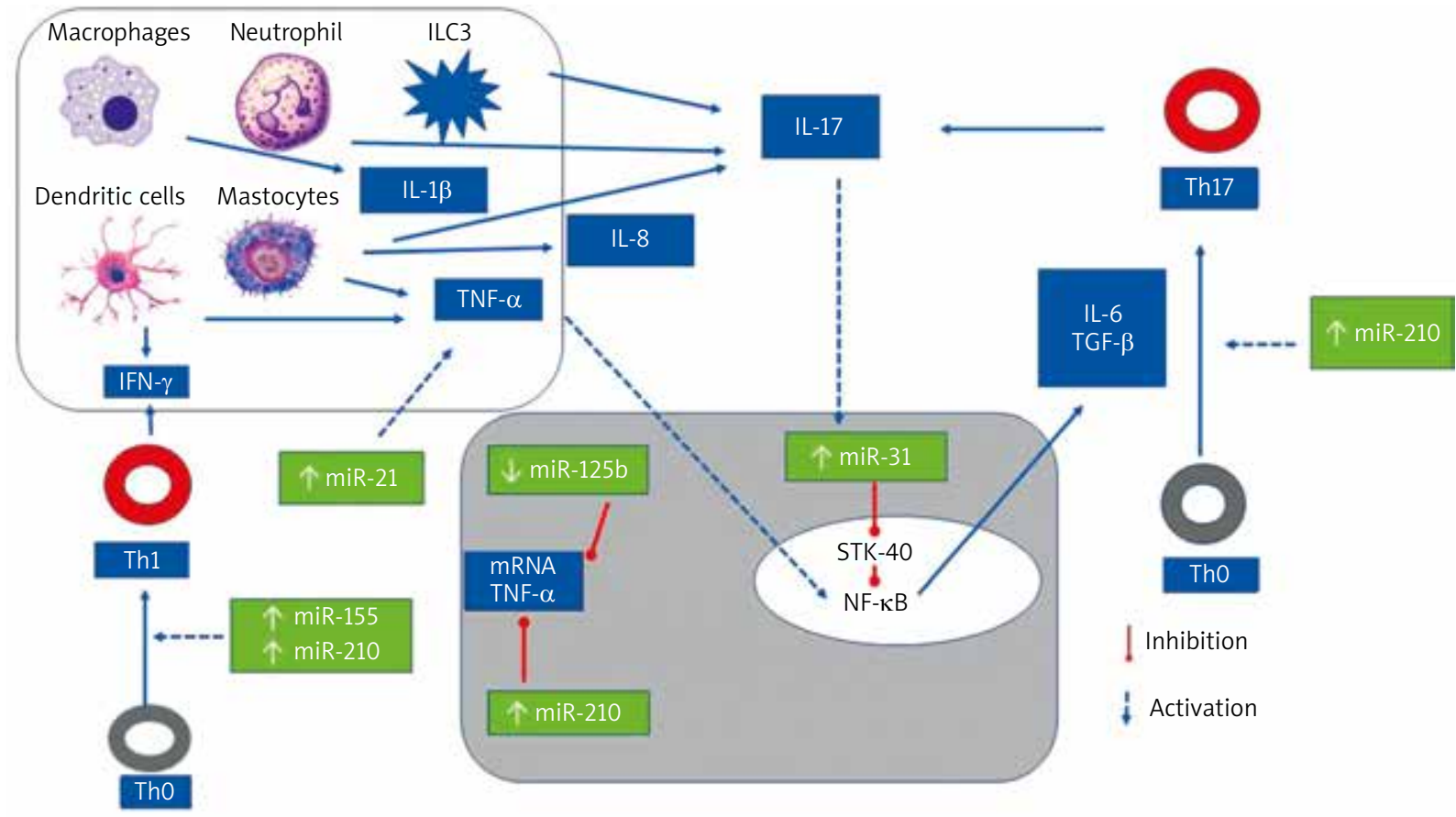

Figure 3. The role of selected mi-RNAs in regulation CD4(+) Th cells differentiation and cytokines synthesis

the expression of IL-4, a cytokine that characterizes the Thelper (Th)2 phenotype, miR-155 promotes expression of interferon $\gamma($ IFN- $\gamma)$ and differentiation of ThO cells towards a Th1 phenotype. Their target genes are SOCS1 (suppressor of cytokine signaling 1) and CTLA4 (cytotoxic T-lymphocyte associated protein 4). SOCS1 is a negative regulator of JAK/STAT and NFKB pathways playing the role in regulation of Treg and Th1 and Th17 differentiation, cytokines and TNF- $\alpha$ production. CTLA4 is the protein of Treg cells which inhibit T effectors cells. A study done by Xu et al. indicated that MiR-155 promotes keratinocyte proliferation and inhibits apoptosis by PTEN 11 signaling pathway in psoriasis [113]. In keratinocytes, miR-155 is induced by TNF- $\alpha$ and IFN- $\gamma$. As a proinflammatory miRNA, via positive feedback, miR-155 increases the production of TNF- $\alpha[69,99,104,114,119]$.

miR-210 induces Th17 and Th1 differentiation and inhibits Th2 differentiation through STAT6 and LYN repression [106]. FOXP3 playing the major role in Treg differentiation is a miR-210 target gene. miR-155 impairs the immunosuppressive functions of Tregs in CD4(+) from healthy controls, while inhibition of miR-210 reverses the immune dysfunction in T cells from psoriasis patients [115]. Overexpression of miR-210 leads to an increased proinflammatory cytokine (IFN- $\gamma$ and IL-17) expression and decreased regulatory cytokine (IL-10 and TGF- $\beta$ ) expression in CD4+ T cells [115].

miR-31 enhances NF- $\kappa$ B signaling; modulates inflammatory cytokine and chemokine production in keratino- cytes and regulates keratinocyte proliferation [102, 103]. The target of miR-31 is the gene of protein phosphatase 6 (ppp6c), acting as a negative regulator that restricts the $\mathrm{G} 1$ to $\mathrm{S}$ phase progression. The rise of miR31 directly inhibits ppp6c expression, thus enhancing keratinocyte proliferation. Moreover, miR-31 regulates the production of inflammatory mediators (TNF- $\alpha$, IL-1, IL-6, IL-17 and IL-22) and stimulates leukocyte chemotaxis, thus inhibiting miR-31, which may be a potential therapeutic option in psoriasis [69, 102, 103, 105, 118, 119, 136].

miR-21 is overexpressed in psoriatic skin lesions, psoriatic epidermal cells, dermal T cells and in blood samples, and plays a major role in psoriasis and correlates with an elevated TNF- $\alpha$ mRNA expression. miR-21 is involved in TGF- $\beta 1$ signaling pathway regulation and downregulates metalloproteinase inhibitor-3 (TIMP-3) in keratinocytes. TIMP-3 inhibits the TNF-converting enzyme, a disintegrin and metalloprotease 17 (ADAM17), which converts the inactive form of TNF into its soluble, activated TNF configuration [69, 103-105, 118, 119, 122, 138].

miR-99a as well as mi-125b are specifically downregulated in psoriasis. Both are presented in dermal inflammatory infiltrates of psoriatic skin; they are also expressed in T helper type-17 (Th17) cells [127].

miR-99 is downregulated particularly in keratinocytes and the upper layer of the epidermis [104, 119, 125]. It targets IGF-1R, which enhances the proliferation of basal layer cells in patients with psoriasis, stimulating hyperplasia and hyperkeratosis [99]. 
miR-125b targets are FGFR-2, TNF- $\alpha$, P63 and NOTCH1 genes. The diminished expression of such miRNAs consequently leads to an increased keratinocyte proliferation rate, together with altered differentiation and an upregulated inflammatory cascade by de-repressed mRNA for TNF- $\alpha$ (Table 3).

\section{Serum miRNA level as a biomarker of disease prognosis and treatment}

Serum levels of miR-33, miR-126, miR-223, and miR143 , among others, have been proposed as potential biomarkers of disease [114, 127]. miR-223 and miR-143 are found to be significantly correlated with the PASI (Psoriasis Area and Severity Index), suggesting their usefulness as biomarkers for disease severity in psoriasis [127].

Treatment of patients with methotrexate significantly decrease miR-223, and miR-143 in patients' blood [127]. In another study, anti-TNF therapy significantly downregulates expression, in the blood of psoriatic patients, of miR0106, miR-26b, miR-142-3p, miR-223, and miR-126 [137].

These observations suggest that some serum miRNAs may serve as potential biomarkers for disease severity and therapy response in psoriasis. Some new data indicate usefulness of anti-miRNAs strategy in therapy of psoriasis.

\section{miRNAs as the new therapeutic option in psoriasis}

Many studies showed that modulating specific miRNAs had a therapeutic effect on keratinocytes [139]. Xu et al. reported that overexpression of miR-125b inhibited keratinocyte proliferation and promoted differentiation via inhibiting its direct target, FGFR2, in primary human keratinocytes [104]. Guinea-Viniegra et al., in an animal model has shown that anti-miR-21 has been to be effective in treating psoriasis. By contrast, it was identified that TGF- $\beta 1$ could upregulate miR-31, while inhibition of miR-31 resulted in suppression of IL-1 $\beta$ and IL- 8 in human primary keratinocytes [103]. Overexpression of miR-210 led to an increased proinflammatory cytokine (IFN- $\gamma$ and IL-17) expression and decreased regulatory cytokine (IL-10 and TGF- $\beta$ ) expression in CD4+ T cells [115]. These experimental data provide important clues to help elucidate the pathogenesis of psoriasis and implicate that promotion of miR-125b while inhibition of miR-31 or miR-210 may also be potential therapeutic options to psoriasis [139, 140].

\section{Genetic polymorphisms that affect miRNA activity might be relevant in the pathogenesis of psoriasis}

Pivarcsi et al. in an excellent review summarize new information about the genetic polymorphisms which af- fect miRNA activity and have functional consequences to psoriasis pathogenesis. Authors suggested that alterations in miRNA-mediated gene regulation can contribute to psoriasis in the following ways:

1. Single nucleotide polymorphisms (SNPs) in psoriasisassociated miRNA genes can affect the activity of a miRNA, altering the set of targets regulated by it, or, interfering with its biogenesis.

2. Single nucleotide polymorphisms in the 3'UTR of psoriasis-associated miRNAs can alter recognition by miRNAs (destruction or creation of miRNA binding sites).

3. RNA-editing resulting in miRNA isoforms (isomiRs) with an altered set of targets regulated by it.

4. Up- or downregulation of miRNAs due to epigenetic, transcriptional regulation or regulation of miRNA processing/stability may lead to disturbed gene regulation in psoriasis.

5. MiRNAs may serve as a new 'language' of intercellular communication in psoriasis [96].

SNPs in the primary transcripts of miRNAs - often long, up to $10 \mathrm{~kb}$ - are more likely to occur [117, 130]. Such miR-SNPs have been described to alter the efficiency by which the primary miRNA transcript is processed and thereby affects the level of the mature, biologically active miRNA.

IsomiRs, natural variations in miRNA ends due to RNA editing, is observed and recent sequencing studies revealed that a number of miRNAs, which are deregulated in psoriasis, such as miR-203, miR-21, miR-31, miR-142, miR-223 and miR-146 express also an altered variant in psoriasis as compared with healthy skin [131].

Many of the already identified SNPs in 3'UTRs of genes associated with psoriasis in GWAS, such as HLA-C, IL-23A, LCE3D, TRAF3IP2, SOCS1 and others, potentially affect miRNA targeting by destroying, creating or altering miRNA binding to these genes.

To date, only one SNP within a miRNA binding site has been linked to psoriasis: a polymorphism abolishing a miR-492 binding site in the basigin gene has been shown to confer a psoriasis risk [135].

In conclusion, altered miRNA expression profiles are displayed in psoriasis. Although the exact roles of miRNAs in psoriasis have not been fully elucidated, a new layer of regulatory mechanisms mediated by miRNAs is revealed in the pathogenesis of psoriasis. miRNAs can regulate differentiation, proliferation and cytokine response of keratinocytes, activation and survival of T cells and the crosstalk between immunocytes and keratinocytes through the regulation of chemokine and cytokine production. Genetic polymorphisms in miRNAs or their target genes, affect miRNA activity and have functional consequences to psoriasis pathogenesis. Circulating miRNAs detected in the blood may become disease markers of diagnosis, prognosis and treatment of disease. The inhibition of expression by some miRNAs may be a new promising therapy option in psoriasis. 


\section{Conclusions}

A huge progress in genotyping technologies in the "genomic era" confirms the polygenic character of psoriasis. More than 50 genetic susceptible markers are associated with the risk of psoriasis. The strongest association of disease with HLA-C*06 locus has been proved in different populations. The majority of psoriasis risk SNPs are situated near the genes encoding molecules involved in adaptive immunity, innate immunity and skin barrier function. Many contemporary studies indicate that epigenetic changes: histone modification, promoter methylations, long non-coding and micro-RNA hyperexpression are considered to be important in the pathogenesis of psoriasis as they regulate abnormal keratinocyte differentiation and proliferation, aberrant keratinocytes inflammatory cells communication, neoangiogenesis and chronic inflammation.

\section{Acknowledgments}

This work was supported by grant of the Polish Ministry of Science and Higher Education no. 02-0066/07/253.

\section{Conflict of interest}

The authors declare no conflict of interest.

\section{References}

1. Farber EM, Nall ML, Watson W. Natural history of psoriasis in 61 twin pairs. Arch Dermatol 1974; 194: 207-11.

2. Russell TJ, Schultes LM, Kuban DJ. Histocompatibility (HL-A) antigens associated with psoriasis. N Engl J Med 1972; 287: 738-40.

3. White SH, Newcomer VD, Mickey MR, et al. Disturbance of HL-A antigen frequency in psoriasis. N Engl J Med 1972; 287: 740-3.

4. Mallon E, Bunce M, Savoie H, et al. HLA-C and guttate psoriasis. Br J Dermatol 2000; 143: 1177-82.

5. Gudjonsson JE, Karason A, Antonsdottir A, et al. Psoriasis patients who are homozygous for the $\mathrm{Hla}-\mathrm{CW}^{*} 0602$ allele have a 2.5-fold increased risk of developing psoriasis compared with Cw6 heterozygotes. Br I Dermatol 2003; 148: 233-5.

6. Henseler T, Christophers E. Psoriasis of early and late onset: characterization of two types of psoriasisvulgaris. J Am Acad Dermatol 1985; 13: 450-6.

7. International Psoriasis Genetics Consortium. The International Psoriasis Genetics Study: assessing linkage to 14 candidate susceptibility loci in a cohort of 942 affected sib pairs. Am J Hum Genet 2003; 73: 430-7.

8. Nair RP, Stuart PE, Nistor I, et al. Sequence and haplotype analysis supports HLA-C as the psoriasis susceptibility 1 gene. Am J Hum Genet 2006; 78: 827-51.

9. Enlund F, Samuelsson L, Enerback C, et al. Analysis of three suggested psoriasis susceptibility loci in a large Swedish set of families: confirmation of linkage to chromosome $6 p$ (HLA region), and to 17q, but not to 4q. Hum Hered 1999; 49: $2-8$.

10. Trembath RC, Clough RL, Rosbotham IL, et al. Identification of a major susceptibility locus on chromosome $6 p$ and evidence for further disease loci revealed by a two stage genome-wide search in psoriasis. Hum Mol Genet 1997; 6: 813-20.

11. Capon F, Burden AD, Trembath RC, et al. Psoriasis and other complex trait dermatoses: from Loci to functional pathways. J Invest Dermatol 2012; 132: 915-22.

12. Tomfohrde J, Silverman A, Barnes R, et al. Gene for familial psoriasis susceptibility mapped to the distal end of human chromosome 17q. Science 1994; 264: 1141-5.

13. Capon F, Novelli G, Semprini S, et al. Searching for psoriasis susceptibility genes in Italy: genome scan and evidence for a new locus on chromosome 1. J Invest Dermatol 1999; 112: 32-5.

14. Mallon E, Newson R, Bunker C. HLA-Cw6 and the genetic predisposition to psoriasis: a meta-analysis of published serologic studies. J Invest Dermatol 1999; 113: 693-5.

15. Lande R, Botti E, Jandus C, et al. The antimicrobial peptide 1137 is a T-cell autoantigen in psoriasis. Nat Commun 2014; 5: 5621.

16. Arakawa A, Siewert K, Stohr J, et al. Melanocyte antigen triggers autoimmunity in human psoriasis. J Exp Med 2015; 212: 2203-12.

17. Krueger J. An autoimmune "attack" on melanocytes triggers psoriasis and cellular hyperplasia. J Exp Med 2015; 212: 2186.

18. Mabuchi T, Hirayama N. Binding affginity and interaction of LL-37 with HLA-C*06:02 in psoriasis. J Invest Dermatol 2016; 136: 1901-3.

19. Jordan CT, Cao L, Roberson ED, et al. PSORS2 is due to mutations in CARD14. Am J Hum Genet 2012; 90: 784-95.

20. Craiglow BG, Boyden LM, Hu R, et al. CARD14-associated papulosquamous eruption: a spectrum including features of psoriasis and pityriasis rubra pilaris. J Am Acad Dermatol 2018; 79: 487-94.

21. Tsoi LC, Spain SL, Knight J, et al. Identification of 15 new psoriasis susceptibility loci highlights the role of innate immunity. Nat Genet 2012; 44: 1341-8.

22. Sun C, Mathur P, Dupuis J, et al. Peptidoglycan recognition proteins Pglyrp3 and Pglyrp4 are encoded from the epidermal differentiation complex and are candidate genes for the PSORS4 locus on chromosome 1q21. Hum Genet 2006; 119: $113-25$

23. De Cid R, Riveira-Munoz E, Zeeuwen PL, et al. Deletion of the late cornified envelope LCE3B and LCE3C genes as a susceptibility factor for psoriasis. Nat Genet 2009; 41: 211-5.

24. Riveira-Munoz E, He SM, Escaramis G, et al. Meta-analysis confirms the LCE3C_LCE3B deletion as a risk factor for psoriasis in several ethnic groups and finds interaction with HLA-Cw6. J Investig Dermatol 2011; 131: 1105-9.

25. Allen MH, Ameen, $\mathrm{H}$, Veal C, et al. The major psoriasis susceptibility locus psors 1 is not a risk factor for late-onset psoriasis. J Investig Dermatol 2005; 124: 103-6.

26. Asumalahti K, Ameen M, Suomela S, et al. Genetic analysis of PSORS1 distinguishes guttate psoriasis and palmoplantar pustulosis. J Invest Dermatol 2003; 120: 627-32.

27. Misiak-Galazka M, Wolska H, Rudnicka L. What do we know about palmoplantar pustulosis. J Eur Acad Dermatol Venereol 2017; 31: 38-44.

28. Onoufradis A, Simpson M, Pink A, et al. Mutations in IL36RN/IL1F5 are associated with the severe episodic inflammatory skin disease known as generalized pustular psoriasis. Am J Hum Genet 2011; 89: 432-7. 
29. Marrakchi S, Guigue P, Renshaw BR, et al. Interleukin36-receptor antagonist deficiency and generalized pustular psoriasis. N Engl J Med 2011; 18: 620-8.

30. Hussain S, Berki DM, Choon SE, et al. IL36RN mutations define a severe autoinflammatory phenotype of generalized pustular psoriasis. J Allergy Clin Immunol 2015; 135: 1067-70.

31. Mossner R, Wilsmann-Theis D, Oji V, et al. The genetic basis for most patients with pustular skin disease remains elusive. Br J Dermatol 2018; 178: 740-8.

32. Mahil S, Catapano M, Di Meglio P, et al. An analysis of IL36 signature genes and individuals with ILIRL2 knockout mutations validates IL-36 as a psoriasis therapeutic target. Sci Transl Med 2017; 9: eaan2514.

33. Madonna S, Girolomoni G, Dinarello CA, et al. The significance of IL-36 hyperactivation and IL-36R targeting in psoriasis. Int J Mol Sci 2019; 20: 3318.

34. Bachelez H, Siew-Eng Choon F, Marrakchi S, et al. Inhibition of the interleukin-36 pathway for the treatment of generalized pustular psoriasis. N Eng J Med 2019; 380: 981-3.

35. Elder JT. Genome-wide association scan yields new insights into the immunopathogenesis of psoriasis. Genes Immun 2009; 10: 201-9.

36. Ellinghaus E, Ellinghaus D, Stuart PE, et al. Genome-wide association study identifies a psoriasis susceptibility locus at TRAF3IP2. Nat Genet 2010; 42: 991-5.

37. Stuart PE, Nair RP, Ellinghaus E, et al. Genome-wide association analysis identifies three psoriasis susceptibility loci. Nat Genet 2010; 42: 1000-4.

38. Nair RP, Duffin KC, Helms C, et al. Genome-wide scan reveals association of psoriasis with IL-23 and NF-kappaB pathways. Nat Genet 2009; 41: 199-204.

39. Huffmeier U, Uebe S, Ekici AB, et al. Common variants at TRAF3IP2 are associated with susceptibility to psoriatic arthritis and psoriasis. Nat Genet 2010; 42: 996-9.

40. Zhang XJ, Huang W, Yang S, et al. Psoriasis genome-wide association study identifies susceptibility variants within LCE gene cluster at 1q21. Nat Genet 2009; 41: 205-10.

41. Sheng $Y$, Jin X, Xu J, et al. Sequencing-based approach identified three new susceptibility loci for psoriasis. Nat Commun 2014; 5: 4331.

42. Tang H, Jin X, Li Y, et al. A large-scale screen for coding variants predisposing to psoriasis. Nat Genet 2014; 46: 45-50.

43. Sun LD, Cheng H, Wang ZX, et al. Association analyses identify six new psoriasis susceptibility loci in the Chinese population. Nat Genet 2010; 42: 1005-9.

44. Li Y, Cheng H, Zuo XB, et al. Association analyses identifying two common susceptibility loci shared by psoriasis and systemic lupus erythematosus in the Chinese Han population. J Med Genet 2013; 50: 812-8.

45. Capon F, Bijlmakers MJ, Wolf N, et al. Identification of ZNF313/RNF114 as a novel psoriasis susceptibility gene. Hum Mol Genet 2008; 17: 1938-45.

46. Strange A, Capon F, Spencer CC, et al. A genome-wide association study identifies new psoriasis susceptibility loci and an interaction between HLA-C and ERAP1. Nat Genet 2010; 42: 985-90.

47. Das S, Stuart PE, Ding J, et al. Fine mapping of eight psoriasis susceptibility loci. Eur J Hum Genet 2015; 23: 844-53.

48. Ray-Jones H, Eyre S, Barton A, et al. One SNP at a time: moving beyond GWAS in psoriasis. J Invest Dermatol 2016; 136: 567-73.

49. Mahil SK, Capon F, Barker JN. Genetics of psoriasis. Dermatol Clin 2015; 33: 1-11.
50. Nair RP, Stuart PE, Nistor I, et al. Sequence and haplotype analysis supports HLA-C as the psoriasis susceptibility 1 gene. Am J Hum Genet 2006; 78: 827-51.

51. Fan X, Yang S, Huang W, et al. Fine mapping of the psoriasis susceptibility locus PSORS1 supports HLA-C as the susceptibility gene in the Han Chinese population. PLoS Genet 2008; 4: e1000038.

52. Enerback C, Nilsson S, Enlund F, et al. Stronger association with HLA-Cw6 than corneodesmosin (S-gene) polymorphisms in Swedish psoriasis patients. Arc Dermatol Res 2000; 292: 525-30.

53. Gudjonsson JE, Karason A, Runarsdottir EH, et al. Distinct clinical differences between HLA-CW*0602 positive and negative psoriasis patients: an analysis of 1019 HLA-C- and HLA-B-typed patients. J Invest Dermatol 2006; 126: 740-5.

54. Szczerkowska Dobosz A, Rębała K, Szczerkowska Z, et al. Correlation of $\mathrm{HLA}-\mathrm{CW}^{\star} 06$ allele frequency with some clinical features of psoriasis vulgaris in the population of northern Poland. J Appl Genet 2004; 45: 473-6.

55. Wu D, Wu Y, Liu JL, et al. Association between HLA$\mathrm{CW}^{\star} 0602$ polymorphism and psoriasis risk: a meta-analysis. Genet Mol Res 2011; 10: 3109-20.

56. Lysell J, Padyukov L, Kockum I, et al. Genetic association with ERAP1 in psoriasis is confined to disease onset after puberty and not dependent on HLA-C*06. I Invest Dermatol 2013; 133: 411-7.

57. Stawczyk-Macieja M, Szczerkowska-Dobosz A, Rębała K, et al. ERAP1 and HLA-C*06 are strongly associated with the risk of psoriasis in the population of northern Poland. Adv Dermatol Allergol 2018; 35: 286-92.

58. Schön MP. Adaptive and innate immunity in psoriasis and other inflammatory disorders. Front Immunol 2019; 10: 1764.

59. de Cid R, Riveira-Munoz E, Zeeuwen E, et al. Deletion of the late cornified envelope LCE3B and LCE3C genes as a susceptibility factor for psoriasis. Nat Genet 2009; 41: 211-5.

60. Zhang XJ, Huang W, Yang S, et al. Psoriasis genome-wide association study identifies susceptibility variants within late cornified envelope (LCE) gene cluster at 1q21. Nat Genet 2009; 41: 205-10.

61. Bergboer GM, Zeeuwen P, Schalkwijk J. Genetics of psoriasis: evidence for epistatic interaction between skin barrier abnormalities and immune deviation. J Invest Dermatol 2012; 132: 320-31.

62. Golan, D, Lander ES, Rosset S. Measuring missing heritability: inferring the contribution of common variants. Proc Nat Acad Sci 2014; 111: E5272-81.

63. Bernstein BE, Meissner A, Lander ES. The mammalian epigenome. Cell 2007; 128: 669-81.

64. Chandra A, Ray A, Senapati S, et al. Genetic and epigenetic basis of psoriasis pathogenesis. Mol Immunol 2015; 64: 313-23.

65. Trowbridge RM, Pittelkow MR. Epigenetics in the pathogenesis and pathophysiology of psoriasis vulgaris. J Drugs Dermatol 2014; 13: 111-8.

66. Pollock RA, Abji F, Gladman DD. Epigenetics of psoriatic disease: a systematic review and critical appraisal. J Autoimmun 2017; 78: 29-38.

67. Zhang P, Zhao M, Liang GP, et al. Whole-genome DNA methylation in skin lesions from patients with psoriasis vulgaris. J Autoimmun 2013; 41: 17-24.

68. Botchkarev VA, Fessing MY, Botchkareva NV, et al. Epigenetic regulation of gene expression in keratinocytes. J Invest Dermatol 2013; 133: 1918-21. 
69. Sonkoly E, Wei T, Janson PC, et al. MicroRNAs: novel regulators involved in the pathogenesis of psoriasis. PLoS One 2007; 2: e610.

70. Potaczek DP, Harb H, Michel S, et al. Epigenetics and allergy: from basic mechanisms to clinical applications. Epigenomics 2017; 9: 539-71.

71. Ovejero-Benito MC, Reolid A, Sánchez-Jiménez P, et al. Histone modifications associated with biological drug response in moderate-to-severe psoriasis. Exp Dermatol 2018; 27: 1361-71.

72. Zhang P, Su Y, Zhao M, et al. Abnormal histone modifications in PBMCs from patients with psoriasis vulgaris. Eur J Dermatol 2011; 21: 552-7.

73. Peterson CL, Laniel MA. Histones and histone modifications. Curr Biol 2004; 27: 546-51.

74. Alaskhar Alhamwe B, Khalaila R, Wolf J, et al. Histone modifications and their role in epigenetics of atopy and allergic diseases. Allergy Asthma Clin Immunol 2018; 14: 39.

75. Chandra A, Senapati S, Roy S, et al. Epigenome-wide DNA methylation regulates cardinal pathological features of psoriasis. Clin Epigenetics 2018; 10: 108.

76. Roberson ED, Liu Y, Ryan C, et al. A subset of methylated CpG sites differentiate psoriatic from normal skin. J Invest Dermatol 2012; 132: 583-92.

77. Zhang P, Su Y, Chen H, et al. Abnormal DNA methylation in skin lesions and PBMCs of patients with psoriasis vulgaris. J Dermatol Sci 2010; 60: 40-2.

78. Gudjonsson JE, Krueger G. A role for epigenetics in psoriasis: methylated cytosine-guanine sites differentiate lesional from nonlesional skin and from normal skin. J Investig Dermatol 2012; 132: 506-8.

79. Ruchusatsawat K, Wongpiyabovorn J, Protjaroen P, et al. Parakeratosis in skin is associated with loss of inhibitor of differentiation 4 via promoter methylation. Hum Pathol 2011; 42: 1878-87.

80. Ruchusatsawat K, Wongpiyabovorn J, Shuangshoti S, et al. SHP-1 promoter 2 methylation in normal epithelial tissues and demethylation in psoriasis. J Mol Med 2006; 84: 175-82.

81. Zhang P, Su Y, Zhao M, et al. Abnormal histone modifications in PBMCs from patients with psoriasis vulgaris. Eur J Dermatol 2011; 21: 552-7.

82. Zhang P, Zhao M, Liang G, et al. Whole-genome DNA methylation in skin lesions from patients with psoriasis vulgaris. J Autoimmun 2013; 41: 17-24.

83. Tsoi LC, Spain SL, Knight J, et al. Identification of 15 new psoriasis susceptibility loci highlights the role of innate immunity. Nat Genet 2012; 44: 1341-8.

84. Maurano MT, Humbert R, Rynes E, et al. Systematic localization of common disease-associated variation in regulatory DNA. Science 2012; 337: 1190-5.

85. Botchkareva NV. The molecular revolution in cutaneous biology: noncoding RNAs: new molecular players in dermatology and cutaneous biology. J Invest Dermatol 2017; 137: e105-11.

86. Sigdel KR, Cheng A, Wang Y, et al. The emerging functions of long noncoding RNA in immune cells: autoimmune diseases. J Immunol Res 2015; 2015: 848790.

87. Tang L, Liang Y, Xie H, et al. Long non-coding RNAs in cutaneous biology and proliferative skin diseases: advances and perspectives. Cell Prolif 2020; 53: e12698.

88. Kretz M, Siprashvili Z, Chu C, et al. Control of somatic tissue differentiation by the long non-coding RNA TINCR. Nature 2013; 493: 231-5.

89. Sonkoly E, Bata-Csorgo Z, Pivarcsi A, et al. Identification and characterization of a novel, psoriasis susceptibility-re- lated noncoding RNA gene, PRINS. J Biol Chem 2005; 280: 24159-67.

90. Guttman M, Rinn JL. Modular regulatory principles of large non-coding RNAs. Nature 2012; 482: 339-46.

91. Tsoi LC, Iyer MK, Stuart PE, et al. Analysis of long non-coding RNAs highlights tissue-specific expression patterns and epigenetic profiles in normal and psoriatic skin. Genome Biol 2015; 16: 24

92. Cabili M, Trapnell C, Goff L, et al. Integrative annotation of human large intergenic noncoding RNAs reveals global properties and specific subclasses. Genes Dev 2011; 25: 1915-27.

93. Qiao M, Li R, Zhao X, et al. Up-regulated IncRNA-MSX2P1 promotes the growth of IL-22-stimulated keratinocytes by inhibiting miR-6731-5p and activating S100A7. Exp Cell Res 2018; 363: 243-54.

94. Rebane A, Akdis CA. Micro Rnas: essential players in the regulation of inflammation. J Allergy Clin Immunol 2013; 132: 15-26.

95. He L, Hannon GJ. MicroRNAs: small RNAs with a big role in gene regulation. Nat Rev Genet 2004; 5: 522-31.

96. Sonkoly E, Ståhle M, Pivarcsi A. MicroRNAs: novel regulators in skin inflammation. Clin Exp Dermatol 2008; 33: 312-5.

97. Pivarcsi A, Ståhle M, Sonkoly E. Genetic polymorphisms altering microRNA activity in psoriasis - a key to solve the puzzle of missing heritability? Exp Dermatol 2014; 23: 620-4.

98. Jiang M, Sun Z, Dang E, et al. TGFbeta/SMAD/microRNA486-3p signaling axis mediates keratin 17 expression and keratinocyte hyperproliferation in psoriasis. J Invest Dermatol 2017; 137: 2177-86.

99. Guinea-Viniegra J, Jiménez M, Schonthaler HB, et al. Targeting miR-21 to treat psoriasis. Sci Transl Med 2014; 6: 225.

100. Masalha M, Sidi Y, Avni D. The contribution of feedback loops between miRNAs, cytokines and growth factors to the pathogenesis of psoriasis. Exp Dermatol 2018; 27: 603-10.

101. Hawkes JE, Nguyen GH, Fujita M, et al. Micrornas in psoriasis. J Investig Dermatol 2016; 136: 365-71.

102. Stepicheva NA, Song JL. Function and regulation of microRNA-31 in development and disease. Mol Reprod Dev 2016; 83: 654-74.

103. Yan S, Xu Z, Lou F, et al. NF-kappaB-induced microRNA-31 promotes epidermal hyperplasia by repressing protein phosphatase 6 in psoriasis. Nat Commun 2015; 6: 7652.

104. Xu N, Meisgen F, Butler LM, et al MicroRNA-31 is overexpressed in psoriasis and modulates inflammatory cytokine and chemokine production in keratinocytes via targeting serine/threonine kinase 40. J Immunol 2013; 190: 678-88.

105. Ichihara A, Jinnin M, Yamane K, et al. MicroRNA-mediated keratinocyte hyperproliferation in psoriasis vulgaris. $\mathrm{Br}$ J Dermatol 2011; 165: 1003-10.

106. Peng H, Kaplan N, Hamanaka RB, et al. MicroRNA-31/factorinhibiting hypoxia-inducible factor 1 nexus regulates keratinocyte differentiation Proc Natl Acad Sci USA 2012; 109: 14030-4.

107. Wu R, Zeng J, Yuan J, et al. MicroRNA-210 overexpression promotes psoriasis-like inflammation by inducing Th1 and Th17 cell differentiation. J Clin Invest 2018; 128: 2551-68.

108. Huang RY, Li L, Wang MJ, et al. An exploration of the role of MicroRNAs in psoriasis: a systematic review of the literature. Medicine 2015; 94: e2030.

109. Bracke S, Desmet E, Guerrero-Aspizua S, et al. Identifying targets for topical RNAi therapeutics in psoriasis: assessment of a new in vitro psoriasis model. J Arch Dermatol Res 2013; 305: 501-12. 
110. Nissan X, Denis JA, Saidani M, et al. MiR-203 modulates epithelial differentiation of human embryonic stem cells towards epidermal stratification. Dev Biol 2011; 356: 506-15.

111. Primo MN, Bak RO, Schibler B, et al. Regulation of pro-inflammatory cytokines TNFalpha and IL24 by microRNA-203 in primary keratinocytes Cytokine 2012; 60: 741-8.

112. Wei T, Xu N, Meisgen F, et al. Interleukin-8 is regulated by miR-203 at the posttranscriptional level in primary human keratinocytes. Eur J Dermatol 2013; doi:10.1684/ ejd.2013.1997.

113. Xu L, Leng H, Shi X, et al. MiR-155 promotes cell proliferation and inhibits apoptosis by PTEN signaling pathway in the psoriasis. Biomed Pharmacother 2017; 90: 524-30.

114. Hou RX, Liu RF, Zhao XC, et al. Increased miR-155-5p expression in dermal mesenchymal stem cells of psoriatic patients: comparing the microRNA expression profile by microarray. Genet Mol Res 2016; 15: doi:10.4238/ gmr.15038631.

115. García-Rodríguez S, Arias-Santiago S, Blasco-Morente G, et al. Increased expression of microRNA-155 in peripheral blood mononuclear cells from psoriasis patients is related to disease activity. J Eur Acad Dermatol Venereol 2017; 31: 312-22.

116. Zhao M, Wang LT, Liang GP, et al. Up-regulation of microRNA-210 induces immune dysfunction via targeting FOXP3 in CD4+ T cells of psoriasis vulgaris. Clin Immunol 2014; 150: 22-30.

117. Sonkoly E. The expanding microRNA world in psoriasis. Exp Dermatol 2017; 26: 375-6.

118. Duan R, Pak C, Jin P. Single nucleotide polymorphism associated with mature miR-125a alters the processing of pri-miRNA. Hum Mol Genet 2007; 16: 1124-31.

119. Joyce CE, Zhou X, Xia J, et al. Deep sequencing of small RNAs from human skin reveals major alterations in the psoriasis miRNAome. Hum Mol Genet 2011; 20: 4025-40.

120. Løvendorf MB, Mitsui H, Zibert JR, et al. Laser capture microdissection followed by next-generation sequencing identifies disease-related microRNAs in psoriatic skin that reflect systemic microRNA changes in psoriasis. Exp Dermatol 2015; 24: 187-93.

121. Liu X, Cheng Y, Chen X, et al. MicroRNA-31 regulated by the extracellular regulated kinase is involved in vascular smooth muscle cell growth via large tumor suppressor homolog 2. J Biol Chem 2011; 286: 42371-80.

122. Garcia-Rodriguez S, Arias-Santiago S, Orgaz-Molina J, et al. Abnormal levels of expression of plasma microRNA-33 in patients with psoriasis. Actas Dermosifiliogr 2014; 105: 497-503.

123. Chatzikyriakidou A, Voulgari PV, Georgiou I, et al. The role of microrna-146a (miR-146a) and its target IL-1R-associated kinase (IRAK1) in psoriatic arthritis susceptibility. Scand J Immunol 2010; 71: 382-5.

134. Lerman G, Avivi C, Mardoukh C, et al. MiRNA expression in psoriatic skin: reciprocal regulation of hsa-miR-99a and IGF-1R. PLoS One 2011; 6: e20916.

135. Roberts JC, Warren RB, Griffiths CE, et al. Expression of microRNA-184 in keratinocytes represses argonaute 2. J Cell Physiol 2013; 228: 2314-23.

126. Tsuru Y, Jinnin M, Ichihara A, et al. MiR-424 levels in hair shaft are increased in psoriatic patients. J Dermatol 2014; 41: 382-5.

127. Choi HR, Nam KM, Park SJ, et al. Suppression of miR135b increases the proliferative potential of normal human keratinocytes. J Invest Dermatol 2013; 134: 1161-4.
128. Lovendorf MB, Zibert JR, Gyldenlove M, et al. MicroRNA-223 and MIR-143 are important systemic biomarkers for disease activity in psoriasis. J Dermatol Sci 2014; 75: 133-9.

129. Koga Y, Jinnin M, Ichihara A, et al. Analysis of expression pattern of serum microRNA levels in patients with psoriasis J Dermatol Sci 2014; 74: 170-1.

130. Paek SY, Han L, Weiland M, et al. Emerging biomarkers in psoriatic arthritis. IUBMB Life 2015; 67: 923-7.

131. Slaby O, Bienertova-Vasku J, Svoboda M, et al. Genetic polymorphisms and microRNAs: new direction in molecular epidemiology of solid cancer. J Cell Mol Med 2012; 16: 8-21.

132. Neilsen CT, Goodall GJ, Bracken CP. IsomiRs: the overlooked repertoire in the dynamic microRNAome. Trends Genet 2012; 28: 544-9.

133. Xia J, Zhang W. A meta-analysis revealed insights into the sources, conservation and impact of microRNA 5'-isoforms in four model species. Nucleic Acids Res 2014; 42: 1427-41.

134. Georges M, Coppieters W, Charlier C. Polymorphic miRNAmediated gene regulation: contribution to phenotypic variation and disease. Curr Opin Genet Dev 2007; 17: 166-76.

135. Zhang W, Yi X, Guo S, et al. A single-nucleotide polymorphism of miR-146a and psoriasis: an association and functional study. J Cell Mol Med 2014; 18: 2225-34.

136. Wu LS, Li FF, Sun LD, et al. A miRNA-492 binding-site polymorphism in BSG (basigin) confers risk to psoriasis in central south Chinese population. Hum Genet 2011; 130: 749-57.

137. Zibert JR, Løvendorf MB, Litman T, et al. MicroRNAs and potential target interactions in psoriasis. J Dermatol Sci 2010; 58: 177-85.

138. Raaby L, Langkilde A, Kjellerup RB, et al. Changes in mRNA expression precede changes in microRNA expression in lesional psoriatic skin during treatment with adalimumab. Br J Dermatol 2015; 173: 436-47.

139. Guinea-Viniegra J, Jiménez M, Schonthaler HB, et al. Targeting MIR-21 to treat psoriasis. Sci Transl Med 2014; 6: 225 re1.

140. Liu Q, Wu DH, Han L, et al. Roles of microRNAs in psoriasis: immunological functions and potential biomarkers. Exp Dermatol 2017; 26: 359-67. 